\title{
Virtual Reality-based Platformer Games Development for Elevating Architectural Heritage Awareness
}

\author{
Ahmad Nasikun ${ }^{1}$, Bagas Y. Wijonarko², Raja Bagus Arief Rahman ${ }^{3}$, Anugerah Galang Persada ${ }^{4}$, Sunu Wibirama ${ }^{5}$
}

\begin{abstract}
As a country with abundant traditional culture, Indonesia is facing serious challenge in conserving them. There is a need to promote the traditional culture to a wider area of people, particularly to the younger generation. Virtual world offers a new way of promoting a nation's culture via Virtual Reality (VR). This research aims to develop a VR-based platformer mobile game to promote cultural awareness in a new and creative way for younger generation. In the game, a player can observe one famous architectural heritage in YogyakartaMesjid Gedhe Kauman-in fun way of game. A survey is conducted to measure its success in reaching the predetermined goals and to measure its user experience (UX). The survey confirm that the VR-based platformer game helps them in learning cultural value of the architecture $(62.5 / 100)$ and it is relatively easy to navigate $(\mathbf{7 2 . 5 / 1 0 0 )}$. Moreover, it has a good user experience (UX) score-all are above 0.8 , meaning that its users are generally comfortable in playing the game.
\end{abstract}

Keywords-Virtual Reality, Serious Game, Cultural Heritage, and User Experience.

\section{INTRODUCTION}

Indonesia is well-known as an archipelago with cultural diversity. Every island has its own unique cultural heritage, such as physical building, traditional art, cultural activities, etc. However, most people do not appreciate culture adequate enough, particularly young generation.

In order to conserve traditional culture in Indonesia, there is a need to promote it to a wider area of people, particularly to the younger generation. The promotion should be done in nontraditional, novel, and attractive way so that it can meet the need of younger generation. On the other hand, digital and virtual world offers a new alternative of interaction between user and application, which is possible to be utilized as medium for promoting cultural heritage [1].

Virtual Reality (VR) technology has grown rapidly and has been quite successful in the market, proven by the existence of various VR devices sold to public, such as Samsung Gear VR, Oculus Rift, etc. These tools are now available in the VR community and have been applied in many fields of medical/ health, entertainment, culture, games, and marketing. Therefore, its use for cultural preservation and recognition is a promising alternative.

Cultural inheritance - in general-can be categorized into two, which are (a) tangible inheritance and (b) intangible

\footnotetext{
${ }^{1,4,5}$ Lecturer, Department of Electrical Engineering and Information Technology, Faculty of Engineering, Universitas Gadjah Mada.

${ }^{2,3}$ Student, Department of Electrical Engineering and Information Technology, Faculty of Engineering, Universitas Gadjah Mada.

${ }^{1}$ Corresponding author: Ahmad Nasikun. Email: ahmad.nasikun@ugm.ac.id
}

inheritance [2]. Intangible cultural heritage includes practice, knowledge, ability, equipment, object, and cultural space that is closely related to society, groups, and its individuals [3] Tangible cultural heritage is physical object that represents the culture of a society, such as historic sites, buildings, monuments, documents, machines, and other artifacts [2]. Both types of cultural heritage are of significant values and must be maintained by the society [4].

This research aims to develop a VR-based mobile game to promote cultural awareness in a new and creative way for younger generation. Its main contribution is the development of VR-based serious games for promoting architectural heritage, using Masjid Gedhe Kauman, Yogyakarta as the case study. The result is tested to measure the user experience design and effectiveness in reaching its goal. The survey is conducted to students at Departement of Electrical Engineering and Information Technology, Faculty of Engineering, Universitas Gadjah Mada.

\section{LITERATURE REVIEW}

Virtual Reality-according to Greenbaum — can be defined as an alternative world filled with computer-generated imagery that can respond to human movement. The simulation world is usually equipped with data accessible with stereophonic eye-wear devices [5]. In more general aspect, VR can also be defined as a real-world or simulation in which users can sense the nuance of existence in that world with the aid of communication means [6]. Although it appears to be a new field, the topic of VR has been studied for a long time, with Sutherland considered to be the first person to research in this field [7], [8].

One main reason for rapid progress of VR is because it offers new ways to develop understanding, technical expertise and cognitive skills without having to put its users in real, sometimes hazardous, conditions [4]. For its fundamental and wide-range impact, VR has been widely used in various fields, such as health [9], games [10], education [11], training [7], culture [12], and military [13]. Today, its use on cultural aspects is highly extensive, one of which is the preservation of cultural heritage.

Cultural heritage can be defined as a message from the past, which survives from generation to generation to the present as a living witness to the traditions of the past [14]. Humans become increasingly aware of unity and consider cultural heritage as important. They assume that protecting cultural heritage is a shared obligation for future generations. Therefore, the preservation of cultural heritage becomes a shared obligation in its authenticity [15].

Serious Games (SG) is defined as a computer game that not only aims to provide entertainment to its users, but it also 
enables the use of 3 dimensional (3D) media for learning and educational purposes in various application domains [2]. The main feature of SG is its ability to support its users to achieve various learning targets through interesting ways/experiences. The 'interesting' aspect of SG makes the user feel more involved in getting information better. The use of Serious Games in the field of cultural heritage can be categorized into four areas: cultural awareness, historical reconstruction, awareness of art/archeological heritage, and awareness of architectural/natural heritage. This research mainly focuses on the use of SG for awareness of architectural heritage.

The use of SG to increase awareness of architectural heritage is the lowest compared to the other three areas [16]. Therefore, there is still a very promising possibility to explore this area, thus this study aims to explore the use of SG to enhance the cultural heritage of architectural heritage, with case studies at the Gedhe Kauman Mosque, Yogyakarta.

There are various systems that have been developed to introduce the culture to the community in an interesting way, including Icura games [14], Discover Babylon, Roma Nova, and Remembering $7^{\text {th }}$ Street. Thos applications are computer graphics-based game applications that aims to introduce culture through game applications.

In addition to games, there are also some applications that aim to allow users to explore architecture heritage in a virtual way using computer-based applications. In China, China Quest Adventure and The China Game app gives users opportunities to recognize the culture and traditions of the country. France also developed Les Fromages de France application that advertises various types of French cheese and its origin.

This research differs from previous researches mentioned above for which it implements the notion of Serious Games in Virtual Reality environment. It also deal with mobile computing development, in which the serious games on architectural heritage is deployed.

\section{METHOD}

In general, the application is developed by using evolutionary process flow with Spiral SDLC development method (Software Development Life Cycle) [17]. In software development, there are five main stages, namely: communication, planning, modeling, construction, and dissemination, as shown in Fig. 1. In the evolutionary process flow the five stages are run in a circular and repetitive pattern in a given cycle. Each cycle runs these five activities to produce a more complete software, developed iteratively from a simple target to a large and complex software application.

\section{A. Softwares and Hardwares}

There are several tools required to build the systems, both hardwares and softwares. Here are the main tools utilized in this research.

1) Samsung Gear VR: Samsung GearVR is a headmounted device (HMD) VR for mobile platform. Developed by Samsung Electronics in collaboration with Oculus, Samsung GearVR is made specifically for Samsung smartphone output. Currently not all smartphones can be used for the VR. By the time of the reseach, only selected smartphone made by Samsung Galaxy variant (A5, Note 5, variant S6, S7 variant, S8 variant) are compatible with Gear VR. Its own HMD has internal sensors required for interaction in VR, such as gyroscope and accelerometer, which connect with smartphones via micro-USB. It also includes touchpad and back button and proximity sensor (whether HMD detection is used or not).

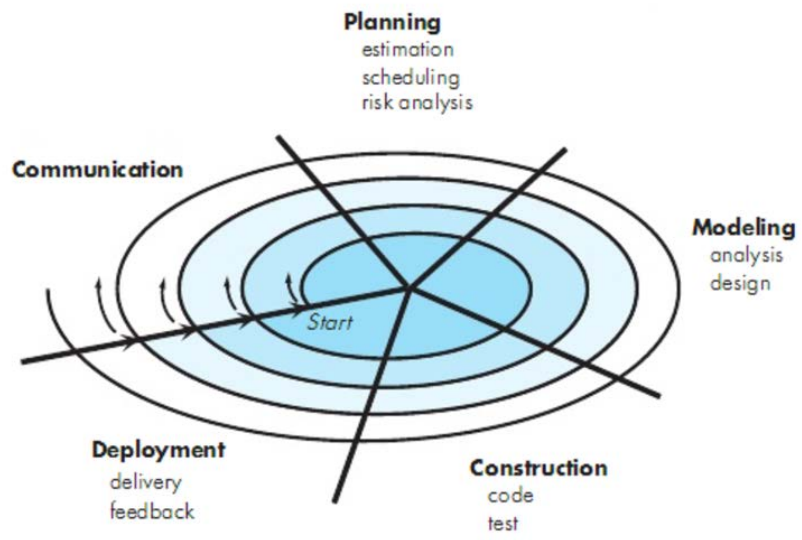

Fig. 1 Spiral SDLC for platformer game.

2) Samsung Galaxy S7 Edge: Samsung Galaxy S7 Edgethat is officially launched by Samsung in 2016-is virtual reality machine with $2.3 \mathrm{GHz}$ octa-core processor. Equipped with built-in 32GB ROM, 4GB RAM and up-to 256 GB of external memory, this Android phone is powerful-yet economically feasible enough-phone for VR. There are multiple sensors embedded on the phone, such as gyro, accelorometer, and proximity sensor that make this phone perfect for VR1.

3) Unity: Unity is a multi-platform game engine, developed by Unity Technologies, primarily used for developing game and simulation applications for computers (desktops), game consoles and mobile devices [2]. Unity is a game engine that has many uses, supports the development of 2D or 3D games, drag \& drop function and scripting using two major programming languages are C\# and JavaScript. Unity is also intended for a variety of API (Application Programming Interface) graphics such as Direct3D, OpenGL, OpenGL ES, WebGL, as well as the latest output for Direct3D 12 variants, and others.

Unity Game Engine is widely used by developers because of its easy-to-understand user interfaces, and free of charge (for Unity Game Engine Personal versions), as well as Unity's ability to create game apps for a variety of platforms, from desktop operating systems (Windows, Linux, MacOS), mobile device operating system (Android, iOS), game consoles (various Playstation variants, Xbox One, Nintendo), up to the latest technologies such as Augmentend Reality and Virtual

http://www.samsung.com/id/smartphones/galaxy-s7-edge-g935/SMG935FZBUXID/ 
Reality. For the development of Virtual Reality-based game applications, Unity supports application development for the Oculus Rift platform, Gear VR, Google Cardboard, HTC Vive, and more.

4) Visual Studio: Microsoft Visual Studio is an integrated development environment (IDE) developed by Microsoft, used to develop various software for Windows operating systems.

The ability of the code editor in Microsoft Visual Studio is very easy for software developers in developing applications, without the need to force developers to read one by one the existing documentation whenever need guidance in doing scripting. Microsoft Visual Studio supports the use of various programming languages, especially C\# (Visual C\#) and JavaScript, allowing for collaboration with Unity Game Engine.

\section{B. Game Design and Scenario}

The proposed game in this research is a platformer-based game application, running on Android phone (Samsung Galaxy S7 Edge). The user will be guided to observe Mesjid Gedhe Kauman Yogyakarta while completing his mission. He will travel both the mosque and surrounding area with the aims of getting more score and avoiding obstacles that will deduct his life point.

The scenario is the following. Almir (main character) is Acehnese prince that is sent to Yogyakarta to learn Islamic culture and tradition in Mesjid Gedhe Kauman, Yogyakarta. In order to complete his mission, he needs to travel around the mosque and area surrounding it. $\mathrm{He}$ will then obtain architectural understanding of the mosque if he can stay long enough in the game. However, there are challenges during this journey of observation. If he is crashed into obstacles, then his life point is deducted by one. Almir is given three life points at the beginning, that both can be deducted once he crashes obstacles and can be increased (up to three) when he bumps into bonus point. The longer he stays in the game, the more information he can get, and thus more point for his journey.

\section{Games and User Experience Testing}

In order to measure the ability of the game to meet its requirement, a users survey is conducted. In addition to that, User Experience Questionnaire (UEQ) is also utilized to measure the level of comfortability of the user in playing the game. Intended for young generation, the survey is conducted to students at DEEIT UGM. Fig. 2 shows the user experience questionnaire.

Laugwitz proposed UEQ which is able to measure six important aspects of UX with 26 short questions only. This questionnaire measures the attractiveness, perspicuity, efficiency, dependability, stimulation and novelty of an application. Users are prompted to score each of the 26 variables with score of 1 to 7 (inclusive), which is then later computed to determine each of the six aforementioned aspects [18].

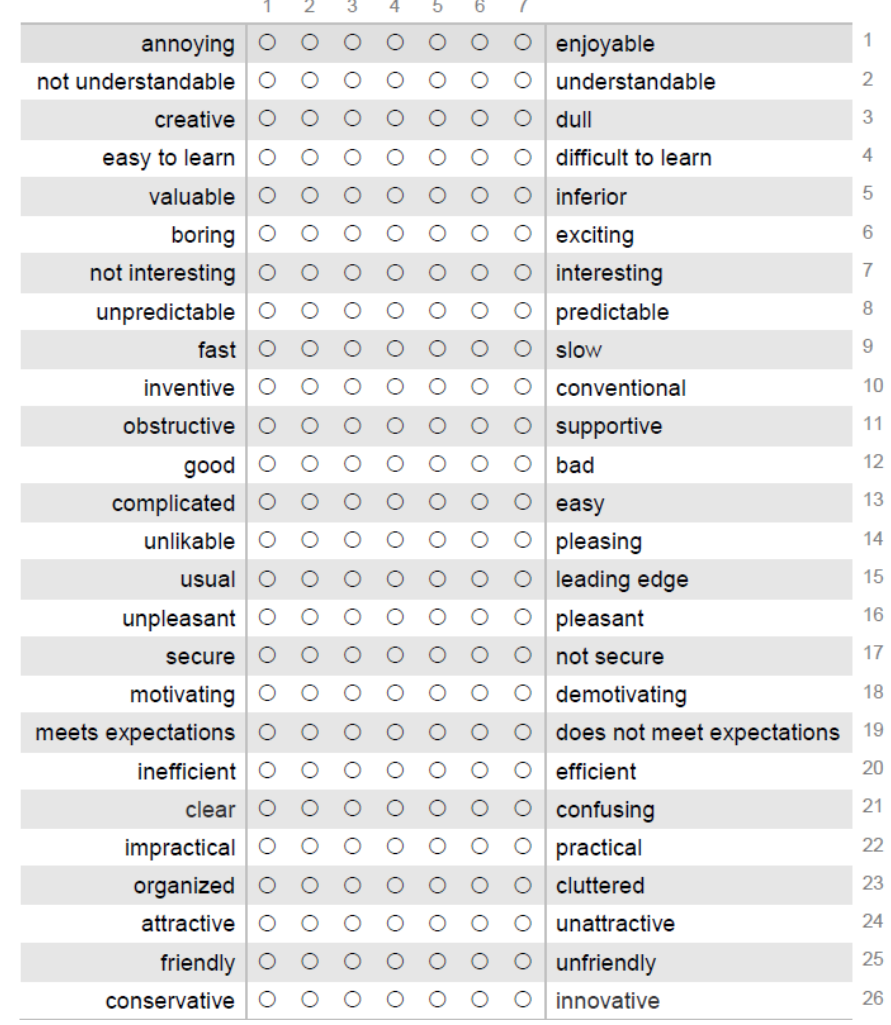

Fig. 2 User experience questionnaire.

Another survey is conducted in order to determine whether the goal of development is achieved by the game application. They are asked whether the app helps them in getting familiar with Indonesian culture (in this case, Mesjid Gedhe Kauman) and whether this VR-based application is interesting for them.

\section{RESULtS}

The game is developed using Unity game engine using Visual Studio integrated development environment. It is then deployed in Samsung Galaxy S7 Edge plus, and viewed using Samsung Gear VR head-mounted device.

Once the game is installed in the machine, one can start to play it. On the main menu, there will be selection of level with background of main architectural heritage (i.e. Mesjid Gedhe Kauman, Yogyakarta). It is expected that user will be starting to be familiar with general structure of the building.

When the user ready to play, he can hover the selection icon to "Start Game", as depicted by Fig. 3. On the main game, the user will be directed to observe the environmental structure of Mesjid Gedhe Kauman, both its outer neighborhood and its internal structure. This aims to provide cultural knowledge to the users.

To add interaction and challenge to the game, there are bonus points and obstacles during the observation. If the user can direct the player to hit bonus icons (i.e. stars) then he will bet additional points. On the other hand, if he crashes into obstacles, then his life point is deducted by one. The user can continue playing until his life point becomes zero. 


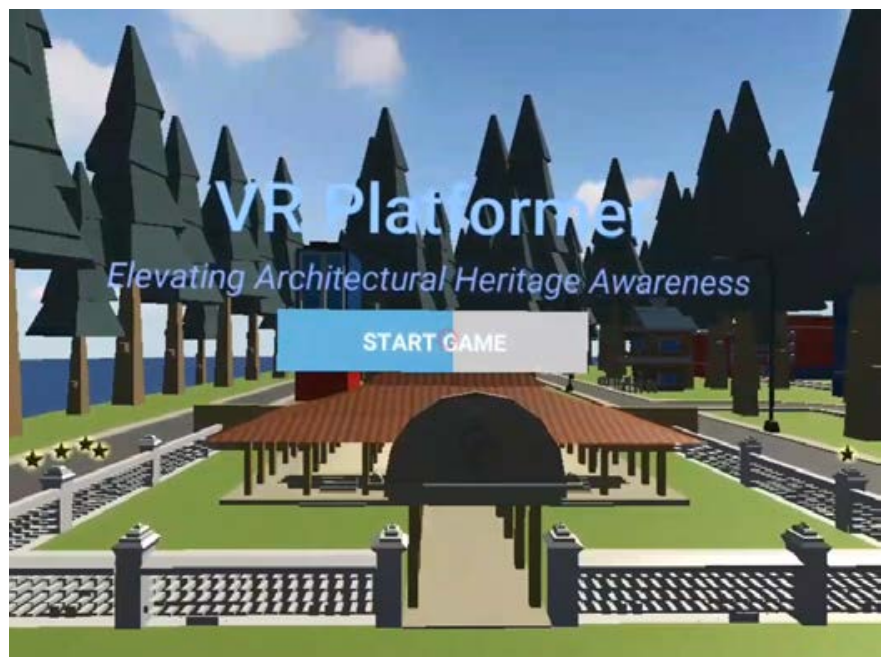

Fig. 3 Home screen of VR-based platformer game.

Fig. 4 shows some screen capture of the game: (a) front part of the mosque and (b) outer neighborhood where traditional javanese houses are present. This aims to introduce understanding of architectural structure to players.

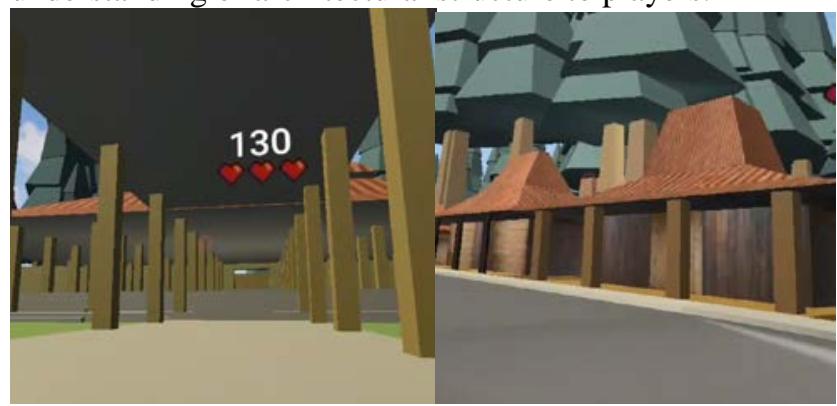

Fig. 4 In-game objects that lead to achitecture awareness; (a) front area of the mosque and (b) traditional Yogyakarta house.

\section{DISCUSSION AND ANALYSIS}

There are 15 students participating in the survey study to measure user experience (UX) of the platformer game, and 8 students for architectural learning aspect evaluation.

The participants gives score of 62.5 (/100), mentioning that the game helps them in learning cultural heritage of Indonesia (i.e. Mesjid Gedhe Kauman) at certain level. They give 80 point when asked how VR can help them in learning cultural heritage. In terms of intuitivity to play the game, the score is 72.5 , meaning that the game is relatively easy to play. It also does not give them too much level of dizziness of 77.5 ( 0 of very dizzy and 100 of not dizzy at all).

In the UX aspects, all of 6 aspects receive more than 0.80 values, meaning that the UX of the game is relatively good, with attractiveness obtains the highest, 1.29. It means that users really like the product. The perspicuity value of 1.05 reflects statement that it is easy to get familiar with the product. 1.02 efficiency score implies that users can solve their problem in the program without serious effort. Users also highly fill in the interaction, shown by 1.08 score in dependability. In general, they are also excited with the product, as implied by the 1.05 value in stimulation. Finally, the 1.07 score in novelty highlights that the product catch users interest. Those values are described in Fig. 5.

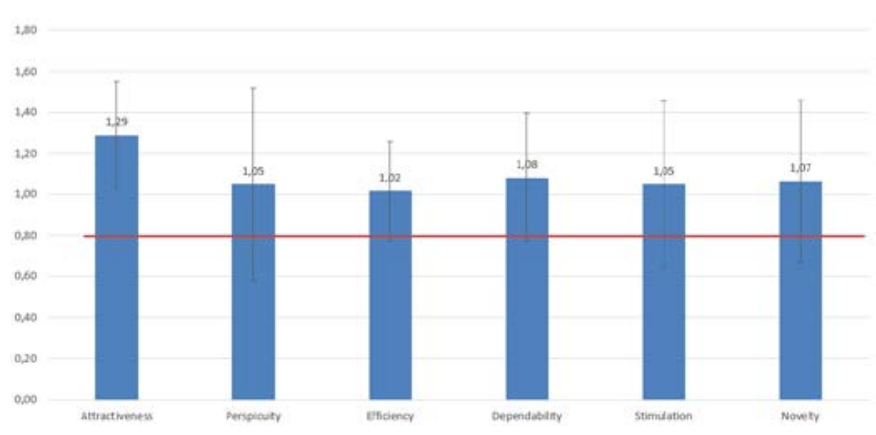

Fig. 5 Measurement of 6 UX aspects of VR-based plaformer game.

\section{CONCLUSION}

A game for elevating cultural awareness is developed in this game, with main object of Mesjid Gedhe Kauman, Yogyakarta. The students survey confirm that it helps them in learning cultural value of the architecture and it is relatively easy to play. In addition to that, its user experience (UX) is high, meaning that it users are generally comfortable in playing the game.

\section{ACKNOWLEDGEMENT}

The authors are highly indebted to generous research funding from Directorate of Research (DirLit) Universitas Gadjah Mada, grant no. 362/DIR.LIT/2017.

\section{REFERENCE}

[1] Hsiao, Hui-Chun. "Reflective Learning through Playing Digital Game The Sims 2." International Conference on Technologies for ELearning and Digital Entertainment. Springer, Berlin, Heidelberg, 2009.

[2] Anderson, Eike Falk, et al. "Developing serious games for cultural heritage: a state-of-the-art review." Virtual reality 14.4 (2010): 255275.

[3] Ahmad, Yahaya. "The scope and definitions of heritage: from tangible to intangible." International journal of heritage studies 12.3 (2006): 292-300.

[4] Tichon, Jennifer, and Robin Burgess-Limerick. "A review of virtual reality as a medium for safety related training in mining." Journal of Health \& Safety Research \& Practice 3.1 (2011): 33-40.

[5] Greenbaum, P. "The lawnmower man”. Film and video, 9 (3), pp. 5862. 1992.

[6] Steuer, J. (1992). Defining virtual reality: Dimensions determining telepresence. Journal of communication, 42(4), 73-93.

[7] Nagendran, M., Gurusamy, K. S., Aggarwal, R., Loizidou, M., \& Davidson, B. R. "Virtual reality training for surgical trainees in laparoscopic surgery”. The Cochrane Library. 27 Aug. 2013.

[8] Sutherland, I. E. The ultimate display. Multimedia: From Wagner to virtual reality. 1965.

[9] Lohse, Keith R., et al. "Virtual reality therapy for adults post-stroke: a systematic review and meta-analysis exploring virtual environments and commercial games in therapy." PloS one 9.3 (2014): e93318.

[10] Saposnik, Gustavo, et al. "Effectiveness of virtual reality using Wii gaming technology in stroke rehabilitation." Stroke 41.7 (2010): 1477 1484.

[11] Freina, Laura, and Michela Ott. "A literature review on immersive virtual reality in education: state of the art and perspectives." The International Scientific Conference eLearning and Software for Education. Vol. 1. " Carol I" National Defence University, 2015.

[12] Guttentag, Daniel A. "Virtual reality: Applications and implications for tourism." Tourism Management 31.5 (2010): 637-651. 
[13] Rizzo, Albert, et al. "Virtual reality goes to war: A brief review of the future of military behavioral healthcare." Journal of clinical psychology in medical settings 18.2 (2011): 176-187.

[14] Froschauer, Josef, et al. "Design and evaluation of a serious game for immersive cultural training." Virtual Systems and Multimedia (VSMM), 2010 16th International Conference on. IEEE, 2010.

[15] Vecco, Marilena. "A definition of cultural heritage: From the tangible to the intangible." Journal of Cultural Heritage 11.3 (2010): 321-324.
[16] Mortara, Michela, et al. "Learning cultural heritage by serious games." Journal of Cultural Heritage 15.3 (2014): 318-325.

[17] Pressman, Roger S. Software engineering: a practitioner's approach. Palgrave Macmillan, 2005.

[18] Laugwitz, Bettina, Theo Held, and Martin Schrepp. "Construction and evaluation of a user experience questionnaire." Symposium of the Austrian HCI and Usability Engineering Group. Springer Berlin Heidelberg, 2008. 